\title{
Physiotherapists' awareness of risk of bone demineralisation and falls in people living with HIV: a qualitative study
}

\author{
Maria Y. Charumbira* ${ }^{*}$, Karina Berner and Quinette Louw
}

\begin{abstract}
Background: Recent research has indicated a seemingly increased propensity for both falls and accelerated bone loss in people living with HIV (PLWH). Physiotherapists play a crucial role in optimising function and quality of life of PLWH through prevention of falls and reducing the harm that results.

Aim: This study aimed to explore physiotherapists' awareness of falls risk and accelerated bone demineralisation in PLWH and their perceptions of current falls prevention strategies in the care of PLWH in selected regions of subSaharan Africa.

Method: An exploratory descriptive qualitative research method was employed to explore physiotherapists' perceptions and experiences regarding bone health and falls in PLWH. In-depth semi-structured telephonic interviews were used to collect data from 21 physiotherapists working in primary HIV care. Transcribed interview data were coded in Atlas.ti.8 and analysed using inductive thematic analysis.

Results: The primary study revealed a lack of awareness by physiotherapists of falls risk and bone demineralisation in PLWH. As such, physiotherapists did not link falls or fractures to HIV or antiretroviral therapy (ART) when they did observe such events during their general patient assessments. However, in retrospect, some physiotherapists were able to recognise risk factors linked to falls in those with HIV. Current services for falls prevention, as perceived by the physiotherapists, were sub-optimal.
\end{abstract}

Conclusion: Physiotherapists may need to be more aware of the potential risk of falls and bone demineralisation in PLWH and routinely assess for these phenomena in both older and younger PLWH.

Keywords: Accidental falls, Bone mineral density, HIV, Physiotherapists, Sub-Saharan Africa

\section{Introduction}

Falls among people living with HIV (PLWH) is an emerging concern. The first study was published recently, in 2012 [1]. Most research, done in high income countries, indicates that reduced bone mineral density (BMD), increased risk of falls and fractures are associated with antiretroviral therapy (ART)

\footnotetext{
* Correspondence: yvonne.kamuti@gmail.com

Division of Physiotherapy, Department of Health and Rehabilitation Sciences, Faculty of Medicine and Health Sciences, Stellenbosch University, P.O. Box 241, Cape town 8000, South Africa
}

exposure, HIV infection itself and traditional risk factors [2-4]. As affordable ART became readily accessible in lower middle-income countries (LMICs), there was a need for more sub-Saharan African data and evidence to guide HIV care within a rehabilitation framework so that PLWH may not only live longer, but do so with improved quality of life (QoL).

The scope of physiotherapy practice in the rehabilitation of PLWH in the ART era is progressively being understood by physiotherapists in LMICs [5, 6]. Randomised controlled trials in Southern Africa have proved

C C The Author(s). 2021 Open Access This article is licensed under a Creative Commons Attribution 4.0 International License, which permits use, sharing, adaptation, distribution and reproduction in any medium or format, as long as you give appropriate credit to the original author(s) and the source, provide a link to the Creative Commons licence, and indicate if changes were made. The images or other third party material in this article are included in the article's Creative Commons licence, unless indicated otherwise in a credit line to the material. If material is not included in the article's Creative Commons licence and your intended use is not permitted by statutory regulation or exceeds the permitted use, you will need to obtain permission directly from the copyright holder. To view a copy of this licence, visit http://creativecommons.org/licenses/by/4.0/ The Creative Commons Public Domain Dedication waiver (http://creativecommons.org/publicdomain/zero/1.0/) applies to the data made available in this article, unless otherwise stated in a credit line to the data. 
the efficacy of physiotherapy on pain management, cardio-pulmonary fitness, strength, and QoL in PLWH $[7,8]$. However, the role of physiotherapy in health promotion and prevention in PLWH is not well understood [9]. Scant evidence exists for physiotherapy interventions that reduce falls [10] or promote bone health $[11,12]$ in PLWH and the role of physiotherapy for HIV at primary care is not clearly understood by the interdisciplinary team [6]. This may result in inappropriate, delayed or non-referral of PLWH who may have benefited from physiotherapy; as well as physiotherapists being sidelined from HIV care policy-making dialogues [13]. Physiotherapists need to be aware of their scope of practice in primary HIV care, particularly falls and fracture prevention, before they can promote it among other health professionals and the community at large [6].

A knowledge gap exists regarding physiotherapists' awareness of falls and bone demineralisation in PLWH or falls prevention practices for this population, especially in sub-Saharan Africa where the greatest burden of HIV exists [14]. Studies regarding physiotherapists' knowledge, attitudes and practice patterns in falls prevention were among older adults of the general population [15-17], and stroke patients [18]. Physiotherapists' perceptions on provision of fall prevention and bone health services were explored in the context of primary care of the general population [19-21]. Physiotherapists play a crucial role in falls prevention in at-risk populations [22]. An evaluation of their current knowledge and practices is an important step in ensuring conformity to best practice [23]. This study therefore aims to explore physiotherapists' awareness of accelerated bone demineralisation and fall risk, and current prevention practices for PLWH in four sub-Saharan African countries. Recommendations from this study may inform physiotherapists and other health care providers involved in the primary care of $\mathrm{PLWH}$, resulting in physiotherapy being valued as an integral component of primary HIV care. It may also form the basis for knowledge translation research for physiotherapist community to conform to evidence-based practice in their care of PLWH, thus improving their health service delivery to this vulnerable population.

\section{Methods}

\section{Design}

An exploratory descriptive qualitative study was used since little is known about this topic. Ethical approval was obtained from the Health Research Ethics Committee of Stellenbosch University (S18/07/137) and permission to conduct the study granted from the health professions or research regulatory bodies in all four countries. Written informed consent was obtained from all participants prior to the interviews. This paper reports on a subset of interview data collected regarding physiotherapists' awareness of fall risk and accelerated bone loss in PLWH. The other interview data has been used to report on health care system challenges affecting falls prevention in PLWH and has been reported in another paper [24]. The report followed the consolidated criteria for reporting qualitative research (COREQ) [25].

\section{Research team}

All investigators were physiotherapists and had experience in qualitative research.

\section{Study participants and recruitment}

We purposively sampled physiotherapists who had at least two years' experience in the primary care of PLWH and were currently working in public primary care facilities in the urban districts of the capital cities of four sub-Saharan African countries (Botswana, South Africa, Zimbabwe, and Zambia). Physiotherapists were excluded if they were not currently registered with their respective physiotherapy boards/councils and if they did not provide written consent. Randomised lists of primary health care (PHC) facilities from each selected district were created using the automated function in Microsoft Excel. Following these lists, the randomly selected PHC facilities were telephoned to identify physiotherapists who met the inclusion criteria. Participant information booklets and consent forms, in which the nature and purpose of the study was fully explained, were electronically mailed to willing participants. Participants who returned their signed consent forms were further contacted to arrange for an interview within a month's timeframe.

According to recommended sample size for phenomenological studies [26], it was proposed a priori that at least 5-6 participants per country would be interviewed. However, purposive sampling prescribes continued sampling until data saturation is achieved, that is until no new significant information is obtained [27].

\section{Data collection and analysis}

Telephonic in-depth interviews took place between December 2018 and July 2019 at pre-appointed times that would not interrupt the participants' clinical practice. All interviews were conducted by the primary investigator (PI) although a second interviewer (KB or QL) was present to ensure consistency and coherence. An interview guide (see Additional file 1) was designed according to similar qualitative studies of rehabilitation specialists' perceptions of falls prevention for the general geriatric population in primary care settings [21, 28] (Table 1).

Further probing questions were used to clarify and gain deeper understanding of responses. No pilot interviews were conducted. However, new relevant issues that arose during preceding interviews were addressed in 
Table 1 Sample of interview questions

Tell me about your experience of treating PLWH. What key functional problems do they present with?

What is your understanding of the risk of falling among PLWH?

What is your understanding of the effect of ART on bones in PLWH?

Have any of your patients living with HIV presented with complaint of falls? What are the common reasons?

How do you assess for falls in your routine care of PLWH?

What are you currently doing for falls prevention in your delivery of care to PLWH?

subsequent interviews. For example, participants reported inadequate undergraduate training resulting in them not being skilled in falls prevention. Therefore, subsequent interviewees were asked questions about their undergraduate training, postgraduate training, and continuous development opportunities regarding falls prevention in PLWH.

Interviews were recorded electronically and transcribed verbatim with the assistance of professional transcribers. The PI transcribed five transcripts to allow immersion into the data and develop the skill [29]. Transcripts were returned to participants to check that transcribed accounts accurately reflected what they had said.

Thematic content analysis with an inductive reasoning approach was applied [30]. Three transcripts were independently coded by three members of the research team (MC, KB, QL) by repeatedly reading transcripts to identify common conceptual themes and patterns. Data triangulation was done by consulting notes taken by interviewers as well as the reflexive notes recorded by the PI. Differences were discussed until consensus was reached. A codebook was created, which was applied to the rest of the transcripts with the aid of qualitative data analysis software Atlas.ti. $8^{\circ}$. Analysis was an iterative process involving repeated cycles of data collection, transcription and analysis [27].

\section{Results}

A total of 30 physiotherapists were invited to participate in this study. Seven physiotherapists declined to participate citing inadequate knowledge regarding the topic while one declined due to lack of time. Two physiotherapists who had given consent to participate could not be contacted on the scheduled appointments despite follow-up. Twenty-one interviews were conducted over a period of seven months. The length of interviews ranged from 22 to $30 \mathrm{~min}$. Table 2 outlines the participants' sociodemographic descriptions.

Table 2 Participants' characteristics

\begin{tabular}{|c|c|c|}
\hline Variable & Number $(n=21)$ & Percentage (\%) \\
\hline \multicolumn{3}{|l|}{ Gender } \\
\hline Male & 4 & 19 \\
\hline Female & 17 & 81 \\
\hline \multicolumn{3}{|l|}{ Work setting } \\
\hline General or Referral Hospital & 13 & 62 \\
\hline District Hospital & 6 & 29 \\
\hline Military Hospital & 1 & 5 \\
\hline Primary Health Clinic & 1 & 5 \\
\hline \multicolumn{3}{|l|}{ Cities (Countries) } \\
\hline Gaborone (Botswana) & 6 & 29 \\
\hline Cape Town Metropole (South Africa) & 4 & 19 \\
\hline Lusaka (Zambia) & 6 & 29 \\
\hline Harare (Zimbabwe) & 5 & 24 \\
\hline \multicolumn{3}{|l|}{ Professional Qualification } \\
\hline BSc. Physiotherapy & 17 & 81 \\
\hline MSc. Physiotherapy & 4 & 19 \\
\hline Age in years (mean $\pm S D$; IQR) & $33.76 \pm 4.22 ; 26-43$ & \\
\hline Years of professional experience (mean $\pm S D$; IQR) & $9.67 \pm 4.22 ; 3-19$ & \\
\hline Years of caring for PLWH (mean \pm SD; IQR) & $8.90 \pm 4.34 ; 3-19$ & \\
\hline
\end{tabular}




\section{Main findings}

Three themes describing physiotherapists' poor awareness of falls risk and bone demineralisation in PLWH and suboptimal fall prevention services were identified (Table 3). Themes, categories, and verbatim supporting quotations are presented below.

\section{Theme one: physiotherapists' (un) awareness of fall risk in PLWH}

Most physiotherapists expressed that they were not aware of the potentially inherent fall risk that could be present in PLWH. The physiotherapists acknowledged that they had not been anticipative of falls in PLWH and had never thought of assessing falls in this population.

'It's difficult for me to explain that question directly ... but specifically to say that this person is HIV positive hence they have this risk of falls, I haven't really observed that.' Participant 14, Zambia.

Some still expressed some level of uncertainty towards this phenomenon being evident in PLWH. Conversely, some who had been initially unaware of falls in PLWH were able to, in retrospect, conclude that falls were a problem in PLWH.

Most participants perceived falls as a geriatric condition that is not particularly characteristic in PLWH.

'... because mostly when we are talking about falls, we are talking about it in the elderly ... but never have you ever heard an emphasis being put on falls with people living with HIV.' Participant 21, Zimbabwe.

A few physiotherapists shared that patients were sometimes unaware of their HIV status because of not routinely testing for HIV. Sometimes patients who were aware of their seropositive status did not reveal it to their physiotherapists, especially when the therapist did not inquire about it. Therefore, the physiotherapists could not always associate presenting comorbidities and impairments with HIV or ART during assessment.

However, less than a third of the physiotherapists, mostly from Botswana and South Africa, recognised the problem of falls in PLWH. Falls were observed in hospitalised PLWH more than community-dwelling, with variable fall rates estimated between 5 and $60 \%$. A few physiotherapists were aware of the risk factors for falls in PLWH, mostly attributing it to balance impairments (due to impaired sensation and loss of proprioception), frailty, muscle wasting, dizziness, ART non-adherence and comorbidities such as depression, tuberculosis, cerebral meningitis, stroke, hypertension, Kaposi Sarcoma and peripheral neuropathy. Two physiotherapists were aware of the negative impact of falls on the lives of PLWH, mentioning consequences such as fear of falling and fall-related fragility fractures.

\section{Theme two: physiotherapists' (un) awareness of bone demineralisation in PLWH}

Most physiotherapists were not aware of the effect of HIV infection or ARVs on increased risk of bone demineralisation in PLWH. They were aware of other side effects of ART such as lethargy, paraesthesia and myalgia but not accelerated bone loss.

'Some of my patients have presented with just general complaints after starting ARV's maybe, they are feeling tired, they are feeling weak and also like general joint pain or body pains as well ... I can't say that it has been on their bones no.' Participant 8, South Africa.

'I don't have enough understanding on that aspect. I only know that ART can have an effect on the nerves ... On the nerves, yes, I know, but on the bones, I am not so much sure.' Participant 11, Zambia.

Table 3 Themes and categories identified from interview data

\begin{tabular}{ll}
\hline Theme & Category \\
\hline Physiotherapists (un) awareness of falls risk & Not anticipatory of falls in PLWH \\
& Falls associated with geriatric population \\
& Unaware of serostatus of PLWH \\
Physiotherapists (un) awareness of bone demineralisation in PLWH & Minority of physiotherapists aware of falls in PLWH \\
& Unaware of effects of HIV or ART on bones \\
Suboptimal fall prevention services & Inaccessible facilities for BMD measurement \\
& Minority of physiotherapists aware of bone demineralisation in PLWH \\
& Fall risk assessment not prioritised \\
& Inadequate primary fall prevention strategies \\
& No screening or assessment tools available \\
\hline
\end{tabular}


Some felt that it would require a bit of research to compare the differences in BMD of PLWH and seronegative patients. All the facilities did not have dual energy $x$-ray absorptiometry (DXA), considered the gold standard for BMD measurement. Most used normal x-rays as their main diagnostic tool for osteoporosis with limited use of computer topography due to its high cost.

A minority of the participants $(n=3)$ supported the fact that ART or HIV infection itself can have a negative impact on BMD, having observed osteoporotic bones on X-rays of PLWH. A few cases of pathological fractures in PLWH were also reported. Some participants attributed bone loss in PLWH to effects of prolonged bed rest rather than effects of ART or HIV infection itself.

\section{Theme three: suboptimal falls prevention services}

All the physiotherapists perceived their current fall prevention practice as suboptimal. This theme described factors mentioned by the physiotherapists that supported this notion.

\section{Fall risk assessment not prioritised in PLWH}

Because they were not aware that PLWH had a high risk of falls, most participants did not routinely assess for falls risk in this population. They prioritised other conditions that PLWH presented with for physiotherapy management. Very few physiotherapists subjectively asked about falls history in PLWH. The physiotherapists were not carrying out multifactorial risk assessments, especially in patients who had not presented with complaints of falls, even though they were able to identify patients with balance impairments during traditional assessments.

'I haven't been doing that much, you know assessing the risk of fall, really unless if it's in the elderly patients, perhaps at the end of neuro rehabilitation just as a screen to see if this patient needs more rehabilitation or not, but in general we don't really assess so much of the risk factors.' Participant 2, Botswana.

One physiotherapist expressed concern regarding the high workload that would result if she did her own routine assessment and preferred to only assess fall risk in patients who had been referred by the doctors. It was also reported that doctors rarely referred PLWH specifically for falls prevention.

\section{Inadequate primary falls prevention strategies}

Most participants reported that they did not have any primary prevention strategies but focused more on secondary prevention for patients who have already experienced falls.
'I don't think we have anything in place for falls prevention. I think we only start treatment when we find that someone has been falling a lot.' Participant 4, Botswana.

Common secondary prevention strategies employed in their current management of falls among PLWH included balance retraining, muscle strengthening, recommending, and training use of assistive devices (Fig. 1).

\section{No screening/assessment tools available}

Lack of rehabilitation-specific generic falls assessment tools in their facilities to guide them in their provision of care to any patient, let alone tools specific to PLWH, emerged as one of the hindrances to fall prevention practice. It was left to individuals' discretion to decide which tool to use for assessment of falls in PLWH.

'Usually, it's not us who do the screening. It's usually done in the wards by the nurses, but we don't have anything in place to use to assess risk of falls, but there should be. There are a couple of tools that could be put in place but currently we are not using anything ... Actually, there is nothing in my department so it's up to an individual to look for what works best for them.' Participant 5, Botswana.

The Berg Balance Scale (BBS) was the most mentioned outcome measure used for assessment of balance, which the physiotherapists carried out as part of their generic assessment without specifically assessing for falls.

\section{(Inadequate) referral to multidisciplinary team by physiotherapists}

Some physiotherapists were aware of the need to involve other health care professionals in their management of falls risk. Health care professionals mentioned included dieticians, ophthalmologists, psychologists, social

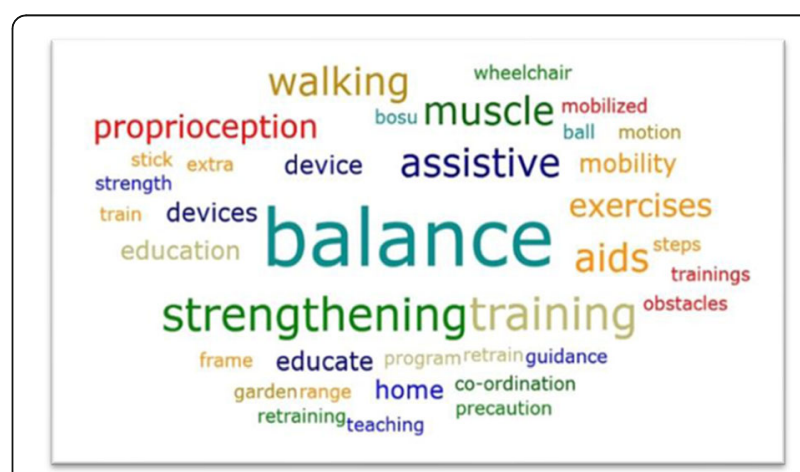

Fig. 1 World cloud showing that the most mentioned fall prevention strategies currently employed by the participants were secondary fall prevention strategies 
workers, and occupational therapists. However, two participants did not see the relevance of referring to other health care professionals once the patient had been referred to them.

'From what I recall we would be the end point ...' Participant 17, Zimbabwe.

Inasmuch as I know people refer these patients to me so that I prevent the falls. I get referrals and then I address the issue. I don't refer to anyone else cause they would have been passed onto me.' Participant 20, Zimbabwe.

\section{Discussion}

This is the first study to explore the awareness by physiotherapists working in primary care facilities in subSaharan Africa of falls risk and bone demineralisation in PLWH and current fall prevention practice. The physiotherapists lacked adequate awareness of falls risk and bone demineralisation among PLWH. They did not necessarily link falls or fragility fractures to HIV or ART and deemed fall prevention services to be sub-optimal. The findings from this study have several implications for physiotherapy practice.

\section{Improve awareness of falls among PLWH by physiotherapists}

The study results demonstrate a need for physiotherapists to be more anticipatory of the risk of falls and bone demineralisation when assessing PLWH. Most physiotherapists were not aware and therefore did not consider falls when assessing PLWH. The main reasons PLWH were referred to physiotherapy were linked to comorbidities such as tuberculosis, cerebral toxoplasmosis, Kaposi sarcoma and polyneuropathies that resulted in pain, altered function, and reduced QoL. The physiotherapists would often prioritise the pain, motor deficits and respiratory dysfunctions. The risk of falls and related fractures were often assessed as a safety precaution before mobilising patients with obvious balance and coordination problems. No comparable studies were identified on awareness of falls in PLWH and physiotherapists (85\%) seem to be more aware of falls in other atrisk populations, such as stroke survivors [18] and geriatrics [17]. Three cross-sectional studies [31-33] in high-income countries reported falls prevalence ranging from $18.6-40.7 \%$ in middle-aged to older PLWH. In LMIC, falls may be prevalent in younger cohorts of PLWH due to the different socio-demographic profile of PLWH or more virulent strains of Clade C HIV [34]; one recent South African study [35] attesting to this possibility. Hence, while Greene et al. [4] recommended routine screening for falls in all PLWH who are 50 years and older, physiotherapists may need to assess for falls in both younger and older PLWH in LMIC.

Most participants' responses were inclined towards hospitalised PLWH post-fall, while information about community-dwelling PLWH mostly emerged after probing. By considering physiotherapists working in primary care settings for inclusion in this study, it was expected that most responses would concern primary falls prevention among community-dwelling PLWH. This finding could mean that less falls occur in community-dwelling PLWH compared to hospitalised PLWH. On the other hand, community-dwelling persons may have experienced more falls than hospitalised persons (perhaps due to greater exposure to external factors contributing to falls e.g. outdoor falls resulting from uneven terrain and vigorous activity) [36]. However, the physiotherapists may possibly be less aware of falls occurring in community-dwelling PLWH because people who fall but do not require healthcare may not report the falls without being asked specifically [37]. While post-fall assessment is important in identifying the cause of prior falls and prevention of further falls [38], risk-screening for falls and education of communities regarding prevention may prevent complications of falls such as injuries, fractures, fear of falling and disability [39].

The need for physiotherapists to be wary of falls in PLWH is further augmented by the finding that physicians rarely referred patients specifically for falls management, but rather for mobility. Chou et al. [40] reported referral of patients with unsteady gaits to physiotherapy as a facilitator to falls risk management. A recent systematic review [41] concluded that PLWH may have gait impairments reflective of fallrelated parameters in older persons. This places the responsibility on physiotherapists to routinely screen for falls in all PLWH referred for mobility management as well as refer appropriately to other health care professionals.

\section{Increase use of standardised screening tools and outcome measures}

Although some participants were aware of the risk factors for falls in PLWH, most did not use standardised screening tools or outcome measures to identify and assess PLWH at risk of falls. A few participants used the BBS as an outcome measure in balance assessments. Physiotherapists' inconsistent use of screening tools for falls has been documented. For example, although 56.9\% of the physiotherapists in one Belgian survey [18] acknowledged the need for fall-risk evaluation at the beginning of treatment, only $32.3 \%$ used standardised outcome measures in screening for falls among their stroke patients. The use of outcome measures is important in evaluating treatment progression as well as 
demonstrating the effectiveness of physiotherapy interventions to relevant stakeholders and policymakers. More research is needed to determine the most predictive tools for assessing risk factors for falls in PLWH.

With regards to screening for BMD loss, most participants were not able to access Dual-energy X-ray absorptiometry (DXA), a tool most predictive in identifying patients at high fall risk because of BMD loss [42]. The physiotherapists mostly relied on less precise X-rays; perhaps because they were more available and less expensive. One study [43] demonstrated calcaneal quantitative ultrasound (QUS) as a feasible alternative to DXA in screening BMD in PLWH, and Berner et al. [35] used it successfully in a resource-limited setting. Perhaps primary health facilities can consider investing in this 'cost effective, portable and ionizing-radiation free tool' [2] to enable PLWH to be routinely screened for bone loss.

\section{Differences between the countries}

A few differences were noted between the countries and health care settings that may have influenced the perspectives of the physiotherapists about the risk of bone demineralisation and falls in PLWH. Botswana and South Africa, both upper-middle income countries, had a few physiotherapists (less than a third) who were aware of falls in hospitalised PLWH. These were mostly from facilities that had gone through the hospital accreditation process which may have reinforced fall prevention as part of patient safety [44]. Another difference was that Botswana outsourced physiotherapy training from highincome countries such as Australia and Ireland [45], where HIV is not priority. This again may have contributed to the physiotherapists' lack of awareness and suboptimal fall prevention practice for PLWH. However, despite these factors, it remained evident that physiotherapists were generally unaware of the risk of falls and bone demineralisation in PLWH, more so in community-dwelling PLWH.

\section{Limitations of the study}

By considering physiotherapists working in urban districts of the selected cities, the results of this study may not be generalised to physiotherapists working in rural primary HIV care settings where different health system structures and patients with different socio-demographic profiles may exist. Also, our sample may have been biased towards a more knowledgeable sample since some participants declined participation in the study because they felt they had insufficient knowledge about the subject.

Further research is needed to establish the magnitude of certain problems highlighted in our study by quantification of data. For example, a quantitative survey would determine what proportion of physiotherapists lack awareness of falls and bone demineralisation in PLWH and therefore whether there is a need to employ interventions to raise an awareness among physiotherapists.

Word clouds (which are based on the concept of font size being proportional to the frequency of word usage) may not have been the most accurate way to display the current falls prevention strategies as they conflate the number of participants who used a word and the number of times all participants used a word [46]. However, word clouds offer a quick means of visual exploratory data analysis that is easy to interpret and display [47]. Thus more important than a count of the proportion of physiotherapists who mentioned a strategy, the word cloud served the purpose of highlighting at a quick glance that the most mentioned strategies were secondary prevention practices.

\section{Conclusion}

Findings from this study indicate that physiotherapists in sub-Saharan Africa are not aware of the potential risk of falls and bone demineralisation in PLWH, and thus do not routinely assess for these phenomena in both older and younger PLWH. Meanwhile, more research is evidently needed regarding falls in PLWH and the effects of BMD loss on falls in PLWH, especially in subSaharan Africa. This evidence may form the basis for revision of undergraduate rehabilitation curricula and continuous professional education needed to improve awareness and delivery of care among physiotherapists and other health professionals involved in primary HIV care. Evidence-based practice will ultimately result in improved health care outcomes and quality of care for PLWH.

\section{Abbreviations}

ART: Anti-retroviral therapy; BBS: Berg's balance scale; BMD: Bone mineral density; DXA: Dual-energy X-ray absorptiometry; HIV: Human immunedeficiency virus; LMIC: Low-to-medium income countries; PLWH: People living with HIV; QoL: Quality of life; QUS: Quantitative ultrasound

\section{Supplementary Information}

The online version contains supplementary material available at https://doi. org/10.1186/s12913-021-06343-1.

\section{Additional file 1.}

\section{Acknowledgements}

The authors are grateful to the physiotherapists who participated in this study for their valuable contributions to the study. We thank One Time

Transcribers for their efficient transcribing services.

\section{Authors' contributions}

The first reviewer (MC) contributed significantly to the drafting and writing of the manuscript as part of her thesis in fulfillment of her master's degree. The second (KB) and third (QL) reviewers as supervisors were substantively involved in the design, interpretation of data and substantive revision of all drafts. All authors read and approved the final manuscript. 


\section{Funding}

The authors gratefully acknowledge the financial support provided by the Medical Research Council of South Africa under a Self-Initiated Research grant (QL). The views and opinions expressed are not those of the funders, but of the authors of the manuscript.

\section{Availability of data and materials}

The participants involved in this study can be identified through the interview transcripts, even after names are removed, because of the few physiotherapists working in primary care. The datasets used and/or analysed during the current study are available from the corresponding author upon reasonable request.

\section{Declarations}

\section{Ethics approval and consent to participate}

This study was conducted in accordance with the principles of the Helsinki declaration and approved by the Stellenbosch University (SU) Human Research Ethics Committee (HREC) (S18/07/137). Written consent was obtained from all participants.

\section{Consent for publication}

Not applicable.

\section{Competing interests}

The authors declare that they have no competing interests.

\section{Received: 20 April 2020 Accepted: 3 April 2021}

\section{Published online: 13 April 2021}

\section{References}

1. Erlandson KM, Allshouse AA, Jankowski CM, et al. Risk factors for falls in HIVinfected persons. J Acquir Immune Defic Syndr. 2012;61(4):484-9. https:// doi.org/10.1097/qai.0b013e3182716e38.

2. Kruger MJ, Nell TA. Bone mineral density in people living with HIV: a narrative review of the literature. AIDS Res Ther. 2017;14(1):1-17. https://doi. org/10.1186/12981-017-0162-y.

3. Premaor MO, Compston JE. People living with HIV and fracture risk. Osteoporos Int. 2020. 2020;31(9):1633-44. https://doi.org/10.1007/s00198-02 0-05350-y.

4. Greene M, Justice AC, Covinsky KE. Assessment of geriatric syndromes and physical function in people living with HIV. Virulence. 2017:8(5):586-98. https://doi.org/10.1080/21505594.2016.1245269.

5. Kinirons SA, Do S. The acute care physical therapy HIV/AIDS patient population: a descriptive study. J Int Assoc Provid AIDS Care. 2015;14(1):5363. doi: 10.1177/23259574134765

6. Nixon S, Cameron C, Mweshi M, et al. "It is an eye-opener that there is a relationship between rehabilitation and HIV": perspectives of physiotherapists and occupational therapists in Kenya and Zambia on the role of rehabilitation with adults and children living with HIV. Physiother Canada. 2016;68(3):290-7. https://doi.org/10.3138/ptc.2015-42gh.

7. Pullen SD, Chigbo NN, Nwigwe EC, Chukwuka CJ, Amah CC, Idu SC. Physiotherapy intervention as a complementary treatment for people living with HIV/AIDS. HIV/AIDS - Res Palliat Care. 2014;6:99-107. https://doi.org/1 $0.2147 /$ hiv.s62121.

8. Mkandla K, Myezwa H, Musenge E. The effects of progressive-resisted exercises on muscle strength and health-related quality of life in persons with HIV-related poly-neuropathy in Zimbabwe. AIDS Care. 2016;28(5):639_ 643. https://doi.org/10.1080/09540121.2015.1125418.

9. Deboer H, Cudd S, Andrews M, et al. Recommendations for integrating physiotherapy into an interprofessional outpatient care setting for people living with HIV: a qualitative study. BMJ Open. 2019;9(5):e026827. https://doi. org/10.1136/bmjopen-2018-026827.

10. Veeravelli S, Najafi B, Marin I, Blumenkron F, Smith S, Klotz SA. Exergaming in older people living with HIV improves balance, mobility and ameliorates some aspects of frailty. J Vis Exp. 2016;(116). Available from: https://doi.org/1 0.3791/54275. Accessed 30 Mar 2020.

11. Santos WR, Santos WR, Paes PP, et al. Impact of strength training on bone mineral density in patients infected with HIV exhibiting Lipodystrophy. J Strength Cond Res. 2015;29(12):3466-3471. https://doi.org/10.1519/jsc. 0000000000001001.
12. Perazzo JD, Webel AR, Alam SMK, Sattar A, McComsey GA. Relationships between physical activity and bone density in people living with HIV: results from the SATURN-HIV study. J Assoc Nurses AIDS Care. 2018;29(4):528-537. https://doi.org/10.1016/j.jana.2018.03.004.

13. Cobbing S, Chetty V, Hanass-Hancock J, Jelsma J, Myezwa H, Nixon SA. Position paper: the essential role of physiotherapists in providing rehabilitative services to people living with HIV in South Africa. SAJP. 2013; 69(1). https://doi.org/10.4102/sajp.v69i1.368.

14. James SL, Abate D, Abate KH, et al. Global, regional, and national incidence, prevalence, and years lived with disability for 354 diseases and injuries for 195 countries and territories, 1990-2017: a systematic analysis for the global burden of disease study 2017. Lancet. 2018;392(10159):1789-1858. https://doi.org/10.1016/S0140-6736(18)32279-7.

15. Obi P, Nwankwo H, Emofe D, Adandom I, Kalu ME. The experience and perception of physiotherapists in Nigeria re: fall prevention in recurrentfaller older adults. Internet J Allied Heal Sci Pract. 2019;17(2):Article 11.

16. Kalu ME, Vlachantoni A, Norman KE. Knowledge about risk factors for falls and practice about fall prevention in older adults among physiotherapists in Nigeria. Physiother Res Int. 2019;24(1):e1742. https://doi.org/10.1002/pri.1742.

17. Peel C, Brown CJ, Lane A, Milliken E, Patel K. A. a survey of fall prevention knowledge and practice patterns in home health physical therapists. J Geriatr Phys Ther. 2008;31(2):64-68. https://doi.org/10.1519/00139143-2 00831020-00005.

18. Baetens T, Peersman W, Cambier D. Falls among stroke survivors: an online survey on perceptions and approaches among physiotherapists in Flanders. Disabil Rehabil. 2009;31(10):818-824. https://doi.org/10.1080/096382808023 55015.

19. Middlebrook S, Mackenzie L. The enhanced primary care program and falls prevention: perceptions of private occupational therapists and physiotherapists. Australas J Ageing. 2012;31(2):72-77. https://doi.org/10.1111/j.1741-6612.2011.00527.x〉

20. Madigan $M$, Cunningham $C$, Blake $C$. A national survey of services for bone health and falls prevention exercise programmes in primary care in Ireland. Physiother Pract Res. 2014;35(1):17-24. https://doi.org/10.3233/PPR-130032.

21. Mackenzie L, Clifford A. Perceptions of primary health staff about falls prevention in primary care settings in the west of Ireland. Br J Occup Ther. 2018;81(9):525-534. https://doi.org/10.1177/0308022618761759

22. Martin JT, Wolf A, Moore JL, Rolenz E, DiNinno A, Reneker JC. The effectiveness of physical therapist-administered group-based exercise on fall prevention. J Geriatr Phys Ther. 2013;36(4):182-193. https://doi.org/10.1 519/JPT.0b013e3182816045.

23. Scurlock-Evans L, Upton P, Upton D. Evidence-Based Practice in physiotherapy: A systematic review of barriers, enablers and interventions. Physiother. 2014;100(3):208-219. https://doi.org/10.1016/j.physio.2014.03.001.

24. Charumbira M, Berner K, Louw Q. Health system challenges affecting falls prevention in persons living with HIV: perspectives from physiotherapists in four sub-Saharan regions. Prim Heal Care Res Dev. (in press). https://doi. org/10.1017/S1463423620000663

25. Tong A, Sainsbury P, Craig J. Consolidated criteria for reporting qualitative research (COREQ): a 32-item checklist for interviews and focus groups. Int J Qual Heal Care. 2007;19(6):349-357. https://doi.org/10.1093/intahc/mzm042.

26. Creswell JW, Poth CN. Qualitative inquiry research design: choosing among five approaches. SAGE: Fourth edition; 2017.

27. Patton MQ. Qualitative research \& evaluation methods. 3rd ed. Thousand Oaks, Calif: Sage Publications; 2002

28. Liddle J, Lovarini M, Clemson L, et al. Making fall prevention routine in primary care practice: perspectives of allied health professionals. BMC Health Serv Res. 2018;18(1):1-9. https://doi.org/10.1186/s12913-018-3414-1.

29. Sutton J, Austin Z. Qualitative research: data collection, analysis, and management. Can J Hosp Pharm. 2015;68(3):226-231. https://doi.org/1 0.4212/cjhp.v68i3.1456.

30. Nowell LS, Norris JM, White DE, Moules NJ. Thematic analysis : striving to meet the trustworthiness criteria. Int J Qual Methods. 2017;16(1):160940691773384. https://doi.org/10.1177/1609406917733847.

31. Greene M, Covinsky KE, Valcour V, et al. Geriatric syndromes in older HIV-infected adults. J Acquir Immune Defic Syndr. 2015;69(2):161-167. https://doi.org/10.1097/qai.0000000000000556.

32. John M, Greene M, Hessol NA, et al. Geriatric assessments and association with VACS index among HIV-infected older adults in San Francisco. J Acquir Immune Defic Syndr. 2016;72(5):534-541. https://doi.org/10.1097/qai. 0000000000001009 
33. Sharma A, Hoover DR, Shi Q, et al. Falls among middle-aged women in the Women's interagency HIV study. Antivir Ther. 2016;21(8):697-706. https:// doi.org/10.3851/FIMP3070.

34. Rademeyer C, Korber B, Seaman MS, et al. Features of recently transmitted HIV-1 clade $C$ viruses that impact antibody recognition: implications for active and passive immunization. PLoS Pathog. 2016;12(7):e1005742. https://doi.org/10.1371/journal.ppat.1005742.

35. Berner K, Strijdom H, Essop M, Webster I, Morris L, Louw Q. Fall history and associated factors among adults living with HIV-1 in the Cape Winelands, South Africa: an exploratory investigation. Open Forum Infect Dis. 2019; 6(10). https://doi.org/10.1093/ofid\%2Fofz401.

36. Chippendale T, Boltz M. The neighborhood environment: perceived fall risk, resources, and strategies for fall prevention. Gerontologist. 2015;55(4):575583. https://doi.org/10.1093/geront/gnu019.

37. Gillespie LD, Robertson MC, Gillespie WJ, et al. Interventions for preventing falls in older people living in the community. Cochrane Database Syst Rev. 2012;(9):CD007146. Available from: https://doi.org/10.1002/14651858. cd007146.pub3. Accessed 30 Mar 2020.

38. Goldberg EM, McCreedy EM, Gettel CJ, Merchant RC. Slipping through the cracks: a cross-sectional study examining older adult emergency department patient fall history, post-fall treatment and prevention. R I Med J. 2017:100(12):18-23.

39. Albert SM, King J, Boudreau R, Prasad T, Lin C, Newman AB. Primary prevention of falls: effectiveness of a statewide program - ProQuest. Am J Public Health. 2014;104(5):e77-84. https://doi.org/10.2105/ajph.2013.301829.

40. Chou WC, Tinetti ME, King MB, Irwin K, Fortinsky RH. Perceptions of physicians on the barriers and facilitators to integrating fall risk evaluation and management into practice. J Gen Intern Med. 2006;21(2):117-122. https://doi.org/10.1111/j.1525-1497.2005.00298.x.

41. Berner K, Morris L, Baumeister J, Louw Q. Objective impairments of gait and balance in adults living with HIV-1 infection: a systematic review and metaanalysis of observational studies. BMC Musculoskelet Disord. 2017;18(1). https://doi.org/10.1186/s12891-017-1682-2

42. Blain $\mathrm{H}$, Rolland $\mathrm{Y}$, Beauchet $\mathrm{O}$, et al. Usefulness of bone density measurement in fallers. Jt Bone Spine. 2014;81(5):403-408. https://doi.org/10.1016/j.jbspin.2 014.01.020.

43. Fantauzzi A, Floridia M, Ceci F, Cacciatore F, Vullo V, Mezzaroma I. Usefulness of calcaneal quantitative ultrasound stiffness for the evaluation of bone health in HIV-1-infected subjects: comparison with dual X-ray absorptiometry. HIV AIDS Research and Palliative Care (Auckl). 2016;8:109117. https://doi.org/10.2147/hiv.s99904. Accessed 30 Mar 2020.

44. International Currently Accredited - COHSASA [Internet]; Available from: http://cohsasa.co.za/health-quality-improvement-international/. Accessed 15 Feb 2021.

45. Nkomazana O, Peersman W, Willcox M, Mash R, Phaladze N. Human resources for health in Botswana: the results of in-country database and reports analysis. African J Prim Heal Care Fam Med. 2014;6(1). https:// doi.org/10.4102/phcfm.v6i1.716.

46. Cidell J. Content clouds as exploratory qualitative data analysis. Area. 2010; 42(4):514-523. https://doi.org/10.1111/j.1475-4762.2010.00952.x.

47. DePaolo CA, Wilkinson K. Get your head into the clouds: using word clouds for analyzing qualitative assessment data. TechTrends. 2014;58(3):38-44. https://doi.org/10.1007/S11528-014-0750-9.

\section{Publisher's Note}

Springer Nature remains neutral with regard to jurisdictional claims in published maps and institutional affiliations.

Ready to submit your research? Choose BMC and benefit from:
- fast, convenient online submission
- thorough peer review by experienced researchers in your field
- rapid publication on acceptance
- support for research data, including large and complex data types
- gold Open Access which fosters wider collaboration and increased citations
- maximum visibility for your research: over 100M website views per year
At BMC, research is always in progress.
Learn more biomedcentral.com/submissions

